\title{
Analysis and Optimization of Material For KTM Motorcycle (Duke 390) Front Alloy Wheel
}

\author{
K. Arjun Kumar \\ Department of Automobile Engineering \\ Rajalakshmi Engineering College, Chennai, Tamilnadu, India \\ J. Kiran Putra \\ Department of Automobile Engineering \\ Rajalakshmi Engineering College, Chennai, Tamilnadu, India \\ V. Monishram \\ Department of Automobile Engineering \\ Rajalakshmi Engineering College, Chennai, Tamilnadu, India \\ Pavan. $\mathrm{P}$ \\ Department of Automobile Engineering \\ Rajalakshmi Engineering College, Chennai, Tamilnadu, India
}

\begin{abstract}
Safety of passengers on board a vehicle has not only been a very important aspect in the design but also for its successful commercial sale. In this research article, the 3D model of the front wheel of KT Duke 390 with its original alloy material (LM 25) was modelled and analysed to estimate the deformation and stresses induced in it at two different speeds under static and dynamic conditions with and without loads acting on it using a commercial FEA software package. Further, the material for the same wheel (with unmodified design) was changed with A350 alloy and similar analysis was carried out for estimating the potential of the selected material as a suitable replacement for the existing alloy. The results of the analysis indicate that the chosen alternative material has performed better in comparison to the current alloy in the wheel with lower deformation rate and stress values.
\end{abstract}

Key words: Material optimisation, two wheelers and alloy wheels.

\section{INTRODUCTION}

The job of an automobile wheel is to support the weight of the vehicle, withstand the stresses generated during torque transmission and vehicle braking. A wheel for automotive application must also be strong enough to provide cushioning effect, should be balanced perfectly and should be as light as possible for better ride comfort. The rim and the ribs of the wheel are the major areas which take up the road loads and shocks due to uneven surface of the road. Figure 1 shows the failure of front alloy wheel in KTM Duke bike. The deformation of the wheel can cause vibrations and will make a tubeless tyre fail in holding the gas pressure. Therefore, careful selection of wheel material, its optimisation and understand its behavior under impact loads ensures optimum performance, long life and safe ride for the motorist. A computer software based approach of solving engineering problems has been well established over the years and its results were found to be close to true value. Hence, a software based FEA approach was adopted in this experimental investigation to carry out the design analysis and material optimisation.

\section{LITERATURE SURVEY}

ManjunathBatli et al.,[1] in their research work, created the 3D model of the wheel and analysed it by applying various load on it and remodeled the same to reduce the deformation. The material was changed from titanium to Al7075. The Al 7075 consisted of 6\% zinc, 2.4\% magnesium, 1.5\% copper, $0.4 \%$ silicon, iron, manganese, titanium, chromium. The data obtained indicate that, the alloy Al 7075(Yield Strength=503MPa) has high strength to weight ratio when compared with magnesium alloy (230 MPa). Al7075 is cheap compared to magnesium alloy. Al 7075 
was more robust and long lasting, whereas it wasn't the case in magnesium alloy. The authors have conclude that Al 7075 can be used as an alternative material in place of magnesium alloy.

Mr. Panduranget al.,[2] have come up with a reverse engineering approach on the existing wheel design to develop a new light weight alloy wheel. Later, the solid model was created by taking the dimensions of the wheel. FEA analysis was done on both the models to estimate the von misses stress for static loading of the wheel. The authors have shown the important modelling, construction steps and various loading strategies. Also, they have discussed the metallurgical features of Mg-alloy \& Al-alloy materials for two wheeler wheels under similar service conditions mentioning their advantages and disadvantages. A new design with reduced weight and number of spokes was presented in place of the existing model. The alloy wheel of Hero passion pro motorcycle was chosen for study. The intention of the investigation was to analyse the load that can be carried by the wheel safely. The paper concludes with the following findings, 1) The maximum stress area was found to be located at spoke rim contact. 2) The alloy (AZ91) is a better replacement for Aluminium alloy wheels. 3) Mg AZ91 material is the best suited for mass reduction of alloy wheel. 4) Low density and high castability for pressure die casting gives $\mathrm{Mg}$ alloy an edge over $\mathrm{Al}$ alloy materials. 5) Material optimisation can be done by lowering the number of spokes. The objective to lower the weight of the alloy wheel has been achieved. 6) 'I' section with four has shown better mechanical behavior compared to "Z" cross section with same number of arms.

N. Satyanarayana et al.,[3] performed a detailed fatigue analysis with radial load on an aluminium alloy wheel A356.2. A computer model of the wheel was created for carrying out static and fatigue analysis using an FEA software. A mesh was created with tetrahedron structure with 10 nodes for the analysis. The analysis was carried out in a static condition constraining the degree of freedom at the wheel diameter and hub portion. The pressure was applied on the rim and the total deformation and shear stress is found out. Also by using the S-N curve of A356.2, the fatigue life of the alloy wheel was found out.

Hrishikesh Joshi et al.,[4] in their research article carried out the analysis and topological optimization of the front wheel of a two wheeler. The existing design of the wheel was modelled, metallurgical testing and mechanical testing were done so as to obtain the chemical composition and mechanical properties. The mass of alloy wheel was reduced by optimization of the design as well as changing of the aluminium alloy 201.0-T43 to Al 7075. Both mechanical and metallurgical properties of the new alloy Al 7075 were taken for the analysis and structural deformation with stress were found out for both static as well as dynamic conditions.

KalyaniRadha et al.,[5] have modelled the wheel of a two-wheeler racing bike using a commercial modelling package for five different materials viz. LM 25, LM25TB7, LM 25TE, LM25TF and AM60A and conducting the tests: static and fatigue analysis using the Cosmos software by lowering the number of spokes from 5 to 4 in the existing model. The induced stresses in the 5-spokes Aluminium Alloy wheel (LM 25TF) was 2.34 MPa was less compared with the Magnesium alloy (AM60A), Al-alloys (LM 25, LM 25TB7, LM25TE) wheels with same number of spokes. Similarly, stress value in the 4-spokes Aluminium Alloy wheel (LM 25TF) 2.22 MPa was less as compared with the stress in 4-spokes Magnesium alloy (AM60A), Al-alloys (LM 25, LM 25TB7, LM25TE). The fatigue life of the magnesium alloy was better than aluminium alloy. The alloy wheel with LM 25TF showed a reduced stress value when the fillet radius was reduced by $1 \mathrm{~mm}$.

Liangmo Wang et al.,[6]in their research article have proposed a better way for evaluating the fatigue life of aluminium wheels. The authors used the ABAQUS software to create 3D of the the aluminium wheels for fatigue simulation studies. The stress levels were calculated based on the consideration of the effects of average load, size, notch sensitivity, surface quality and other factors. The fatigue life of aluminium wheels was projected based on the stress amplitude and S-N curve of the aluminium alloy. The experimental results showed that the basic wheel failed the test due crack formation around the hub bolt and it was synonymous with the simulation. The proposed method estimated that the life cycle of the wheel has improved to over ten thousand times and comfortably the design. Further, the results have that the technique of combining finite element analysis and nominal stress method was an effective way to predict the fatigue life of aluminium wheels. 

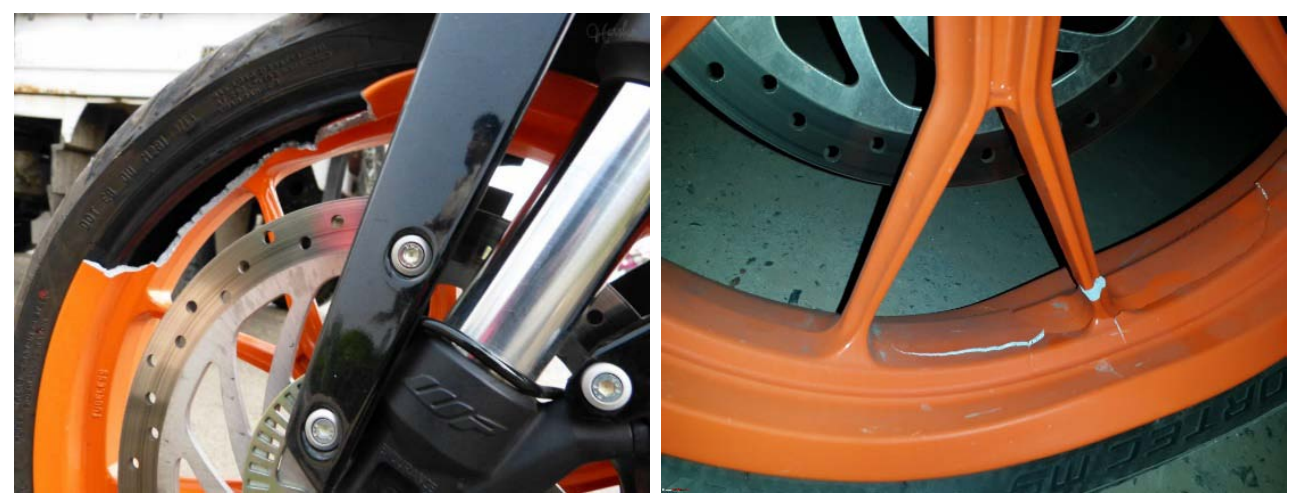

Figure 1. Cracked Duke A390 alloy wheel

\section{MethodOLOGY}

The alloy wheel was analysed at two conditions, i.e., wet weight and with two average Indian adults (65kgs each) riding on the motorbike.

\section{A. Static Condition (wet weight)}

In this condition, the front wheel experience less reaction force acting on it, whereas, the rear wheel receives the maximum load due to its proximity to the centre of gravity of the vehicle.

B. Dynamic Condition (wet weight)

Two types of dynamic conditions are taken into account for alloy wheel analysis, they are during deceleration and acceleration of the two wheeler. During acceleration, there will be a shift of weight toward the rear wheel. Thus when the vehicle accelerates, the rear wheel alone will experience an additional force on the hub in addition to the reaction force. During deceleration, there will be a shift of weight towards the front wheel. In addition to the reaction force, a braking force is also experienced by the front wheel. Reaction force at rear wheel and front wheel is obtained from adding and subtracting the added forces (due to acceleration) to the normal reaction forces adding on the wheel.Force acting on the rear wheels and front wheels due to deceleration (braking) is given by subtracting and adding the braking force from normal reaction.

Table 1 Load on the wheel with no rider (wet weight).

\begin{tabular}{cccc}
\hline S.No. & Condition & Wheel & Load (N) \\
\hline 1. & Stationary & Front & 690.427 \\
& & Rear & 810.502 \\
2. & Acceleration & Front & 317.872 \\
& & Rear & 1183.057 \\
3. & Deceleration / Braking & Front & 1435.537 \\
& & Rear & 65.412 \\
\hline
\end{tabular}

Table 2 Load on the wheel with two people (wet weight+ avg. weight of two people)

\begin{tabular}{cccc}
\hline S.No. & Conditions & Wheel & Load (N) \\
\hline 1. & Stationary & Front & 1277.0658 \\
& & Rear & 1499.1642 \\
2. & Acceleration & Front & 587.9608 \\
& & Rear & 2188.2692 \\
3. & Deceleration / Braking & Front & 2955.2758 \\
& & Rear & 120.9542 \\
\hline
\end{tabular}




\section{Meshing and Analysis of the Wheel}

After taking all the required dimension from the wheel under study a 3-D model was created in software. A small piece of the wheel was cut from the outer section using a cutting machine. This piece of the wheel was then tested at an industry certified materials testing laboratory for metallurgical analysis and the following results were obtained.

Table 3 Chemical composition of LM25 (KTM Duke Alloy)

\begin{tabular}{cccccccccc}
\hline Elements & Si & Fe & Cu & Mn & Mg & Ni & Zn & Ti & Al \\
\hline Wt\% & 7.44 & $\mathbf{0 . 1 9 8}$ & $\mathbf{0 . 0 0 9}$ & $<0.002$ & 0.322 & 0.017 & $\mathbf{0 . 0 1 0}$ & $\mathbf{0 . 1 2 9}$ & 91.78
\end{tabular}

The aluminium alloys are designated with a number to denote the chemical composition but it is very difficult to compare this composition with every available alloy in the commercial market. Hence the search of the alloy is filtered into two processes. First, cast alloys were alone used for wheels, this eliminates the other unwanted aluminium alloys from the list. Second step was to narrow down the names of aluminium alloys and their composition with results of the chemical constiutent analysis done earlier. Thus the material used in KTM Duke alloywheel was found to match the composition of LM25, which has a major aluminium composition of $91.78 \%$ of the alloy.

Table 4 Chemical composition of A356 material

\begin{tabular}{cccccccccc}
\hline Elements & Si & Cu & Mg & Mn & Fe & Zn & Ni & Ti & Al \\
\hline Wt\% & 7.20 & 0.02 & 0.29 & 0.01 & 0.18 & 0.01 & 0.02 & 0.11 & 92.16 \\
\hline
\end{tabular}

The properties of LM25 are needed to perform the analysis on the wheel. An alternative material proposed for analysis in this paper was A356 and its mechanical properties and chemical composition were considered for the analysis. The properties required to define a new material in ANSYS are given below.

Table 5 Comparison of physical properties of selected materials

\begin{tabular}{lcc}
\hline Properties & LM 25 Duke Alloy & A356 \\
\hline Density (g/cc) & 2.69 & 2.67 \\
Young's Modulus (MPa) & 71000 & 72400 \\
Poisson's Ratio & 0.33 & 0.33 \\
Bulk Modulus (MPa) & 69608 & 70980 \\
Shear Modulus (MPa) & 26692 & 27218 \\
Tensile Yield Strength (MPa) & 225 & 218 \\
Ultimate Yield Strength (MPa) & 268 & 283 \\
\hline
\end{tabular}

\section{DESIGN \& ANALYSIS}

The general steps involved in static structural and transient structural analysis of wheel are pre-processing, solver and post processing. Pre-processing is the first step of static structural and transient structural analysis. Its major steps include defining engineering data, creating or importing the model to be analysed in the software. The second step involved in analysis is the material definition for the model to be analysed. 


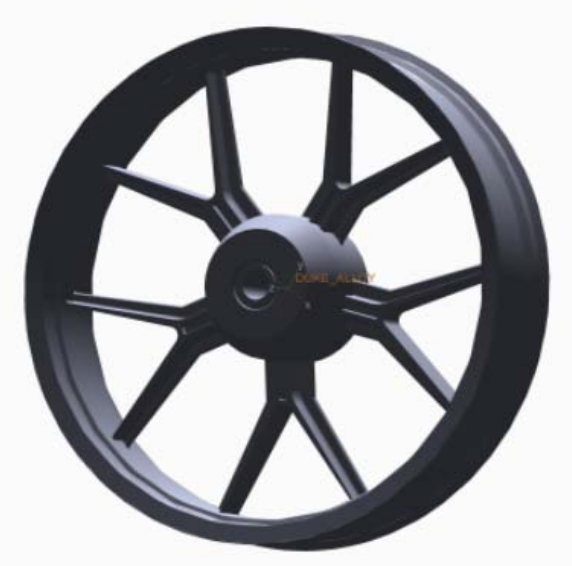

Figure 2. 3D Model of alloy wheel

Meshing and analysis was done in ANSYS workbench.The quality of meshing chosen here was medium mesh with an element size of $10 \mathrm{~mm}$.

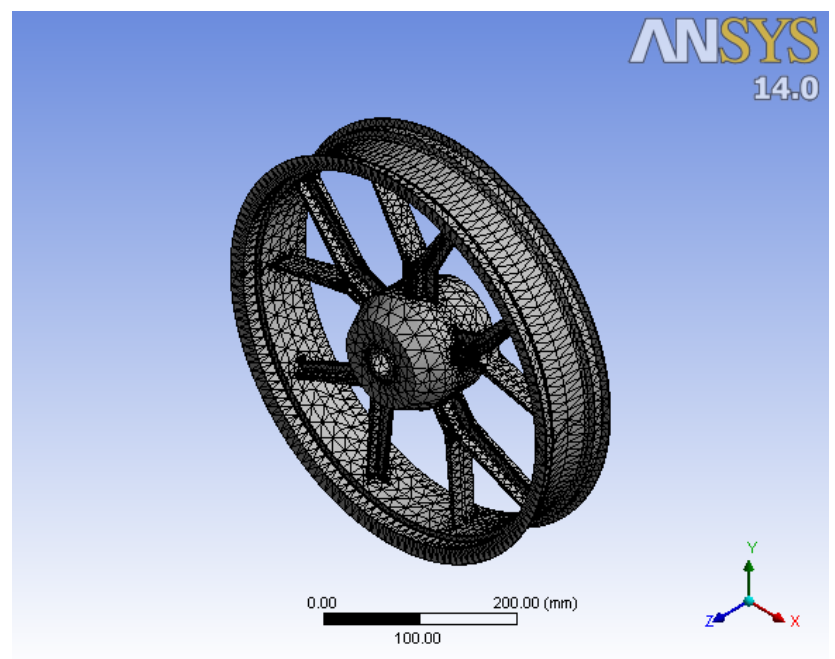

Figure 3. Meshed alloy wheel

A. Static structural analysis 


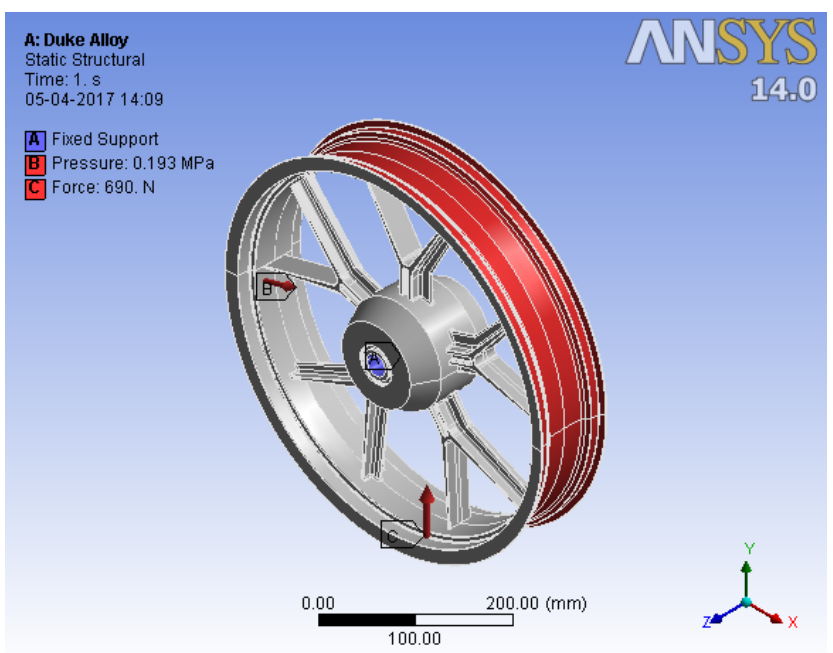

Figure 4. Static boundary and loading conditions

In static structural analysis, a pressure of $0.193 \mathrm{~N} / \mathrm{mm}^{2}$ (28 psi) was applied on the outer surface of the rim. This pressure is the tyre pressure which acts circumferentially across the radius of the rim. The stud axle bolt hole is constrained in all degrees of freedom i.e. fixed. A reaction force acts on the point of contact of the wheel with the ground. This reaction force varies with different static and dynamic conditions.

\section{B. Dynamic structural analysis}

For transient analysis a pressure of $0.193 \mathrm{~N} / \mathrm{mm}^{2}$ (28psi) was applied on the outer surface of the rim. This pressure is the tyre pressure which acts circumferentially across the radius of the rim. The stud axle bolt hole is constrained in all degrees of freedom ie. fixed. Rotational velocity of $64.3 \mathrm{rad} / \mathrm{s}$ and $128.6 \mathrm{rad} / \mathrm{s}$ was applied to the wheel in the $\mathrm{Z}$ direction. $64.3 \mathrm{rad} / \mathrm{s}$ and $128.6 \mathrm{rad} / \mathrm{s}$ correspond to $50 \mathrm{kmph}$ and $100 \mathrm{kmph}$ respectively. A reaction force acts on the point of contact of the wheel with the ground. This reaction force varies with different static and dynamic conditions.

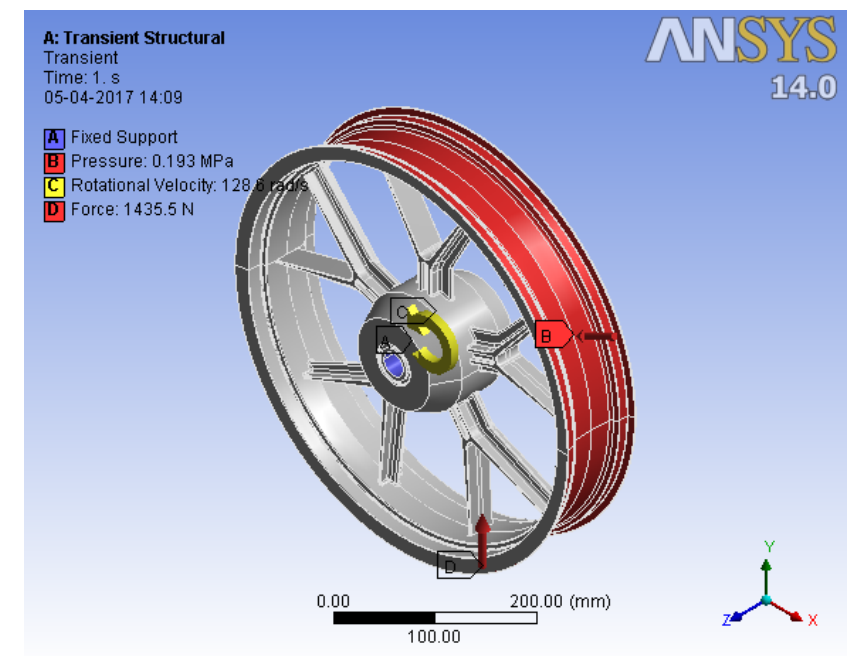

Figure 5.Transient boundary and loading conditions

When solving the model, the load condition according to which structure analysis is done was defined for the wheel model. After the model was analysed for the given conditions, post processing was done and the results of this process are discussed in the following section. 


\section{RESULTS \& DISCUSSION}

Under static wet weight condition, the structural analysis was performed on the alloy. From figure 6 and figure 7 , the maximum deformation for LM 25 (Duke Alloy) was found to be $0.02206 \mathrm{~mm}$ and the maximum deformation for A356 was found to be $0.021637 \mathrm{~mm}$ both occurs at the point of loading.Similarly, the maximum equivalent (VonMises) stress for LM 25 (Duke Alloy) and A356 Alloy was found to be the same at 26.06MPa, which was found to be considerably lower in comparison to the tensile yield and ultimate strength.

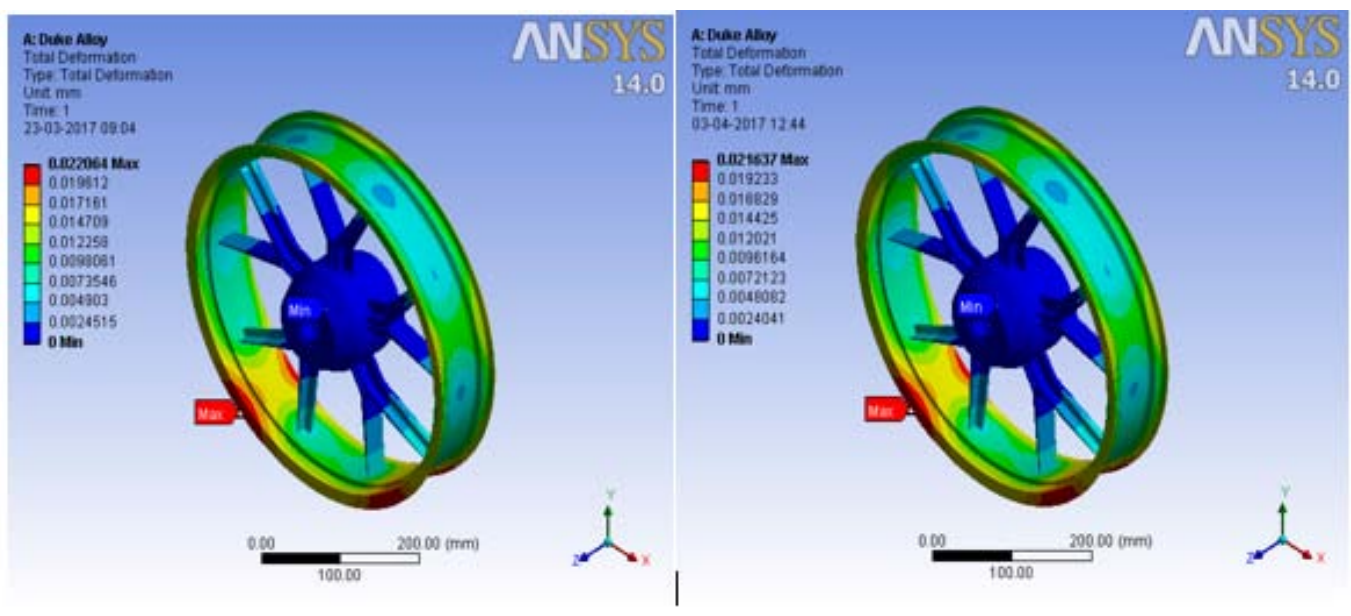

LM25

A356

Figure 6. Total deformation for static condition

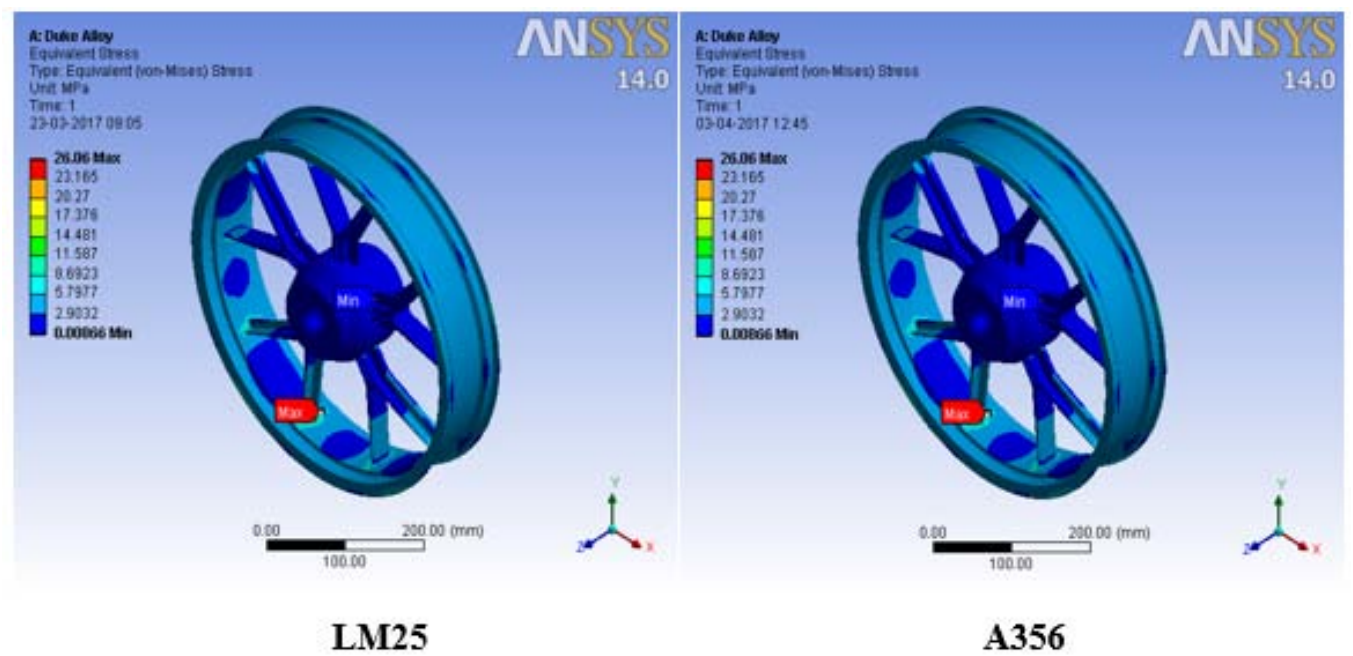

Figure 7. Equivalent von-mises stress for static condition

Figures 8 - 9 indicate the total deformation and equivalent von-mises stress for static condition - front wheels with two people (wet weight + avg. weight of two people). From the figures it is seen that the maximum deformation for LM 25 (Duke alloy) was found to be $0.025972 \mathrm{~mm}$ whereas, the maximum deformation with A356 was found to be $0.02547 \mathrm{~mm}$ both occurs at the same point of loading. The maximum equivalent (von-mises) stress for LM 25 (Duke Alloy) and A356 Alloy was found to be the same at 31.518MPa, which was found to be considerably lower in comparison to the tensile yield and ultimate strength. 


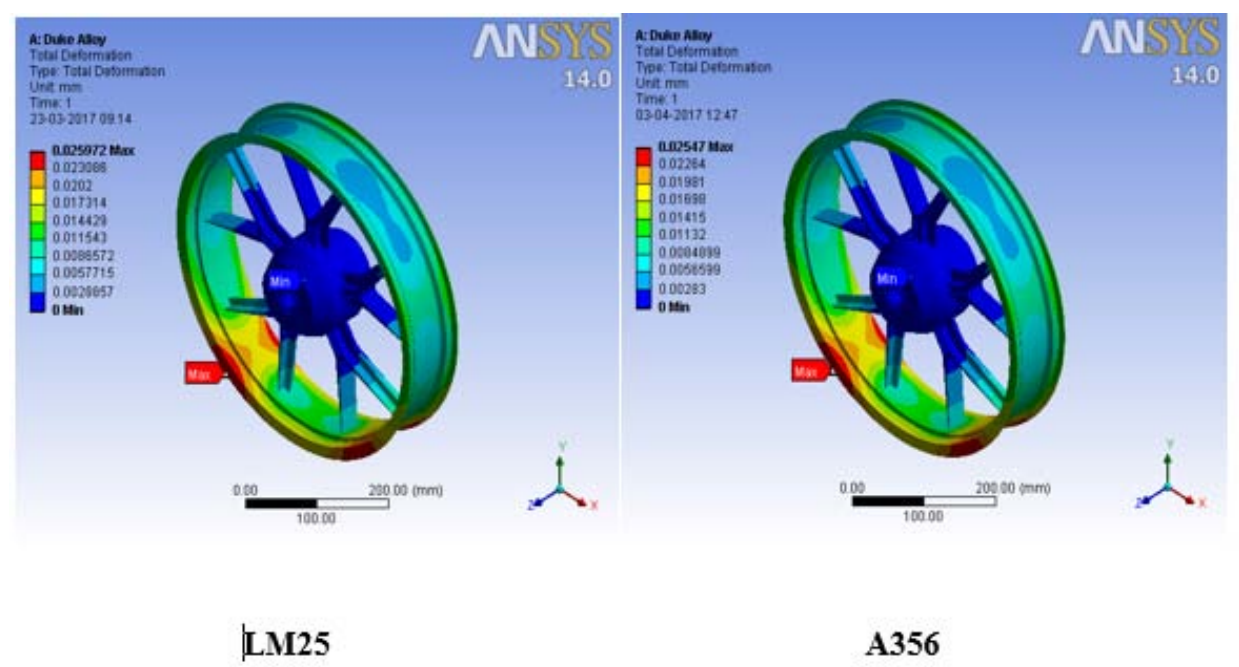

Figure 8. Total deformation for static condition withwet weight and average weight of two people

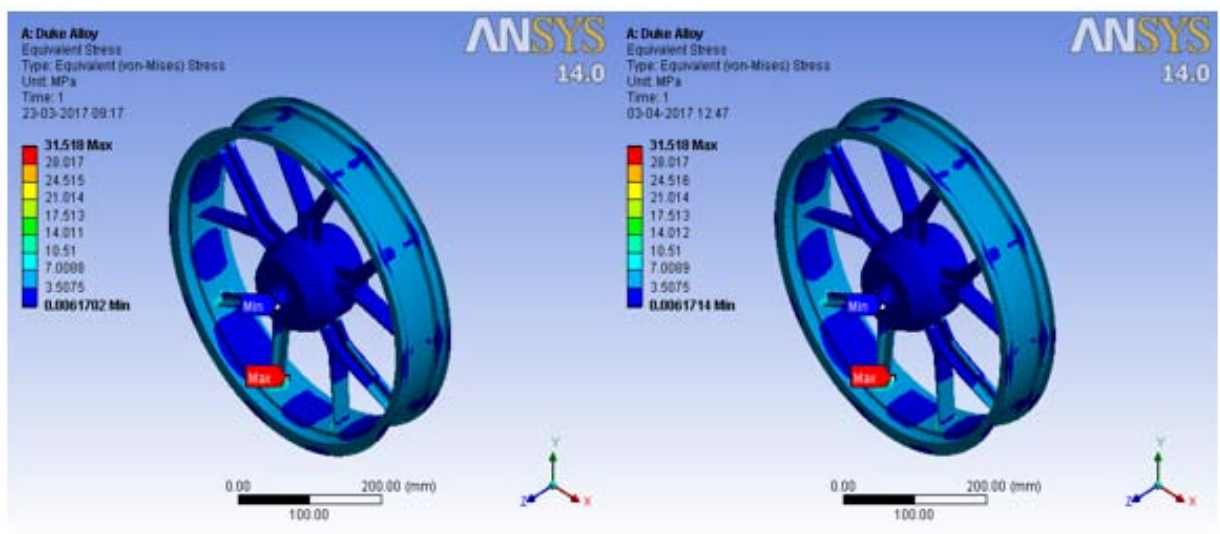

LM25

A356

Figure 9. Total equivalent von-mises stress for static condition with wet weight and average weight of two people

Dynamic acceleration test for $50 \mathrm{kmph}$ and $100 \mathrm{kmph}$ was carried out and figures 10, 11, 12 and 13 shows the total defromation and equivalent von-mises stress for wheel with LM 25 and A356 alloys. 


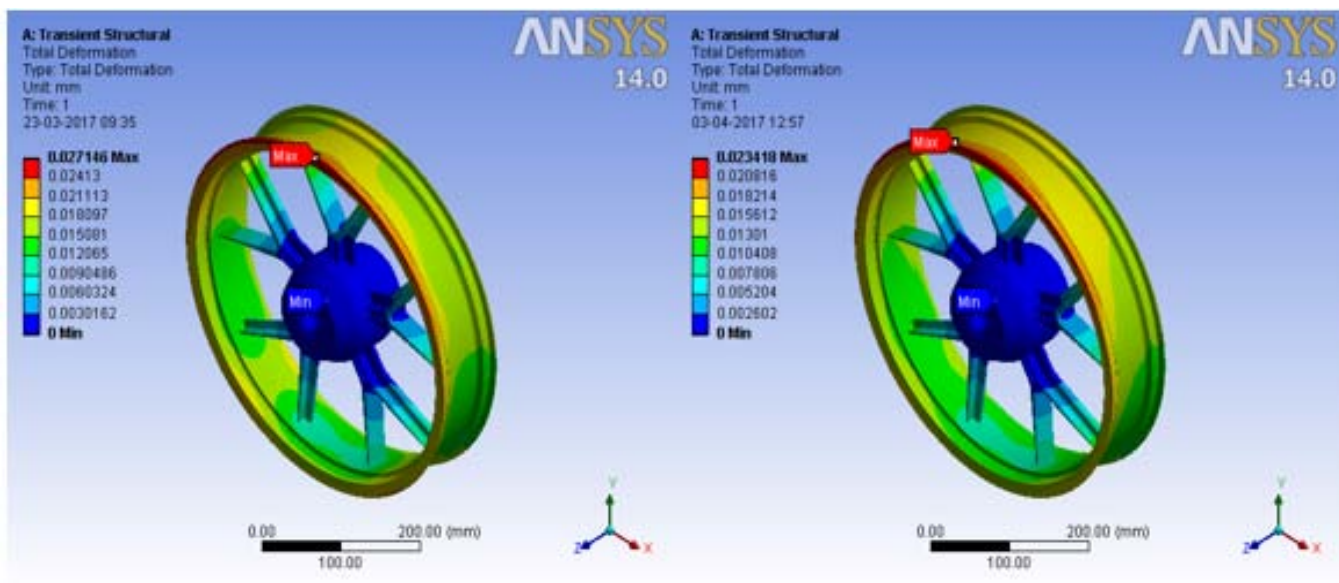

LM 25

A 356

Figure10. Total deformation at speed of $50 \mathrm{kmph}$

Under dynamic acceleration at $50 \mathrm{kmph}$ under wet weight conditions, transient structural analysis was performed on the alloy and the maximum deformation for LM 25 ( Duke alloy ) was found to be $0.027146 \mathrm{~mm}$ whereas, the maximum deformation for A356 was found to be $0.023418 \mathrm{~mm}$ both occurring at the same loading point.

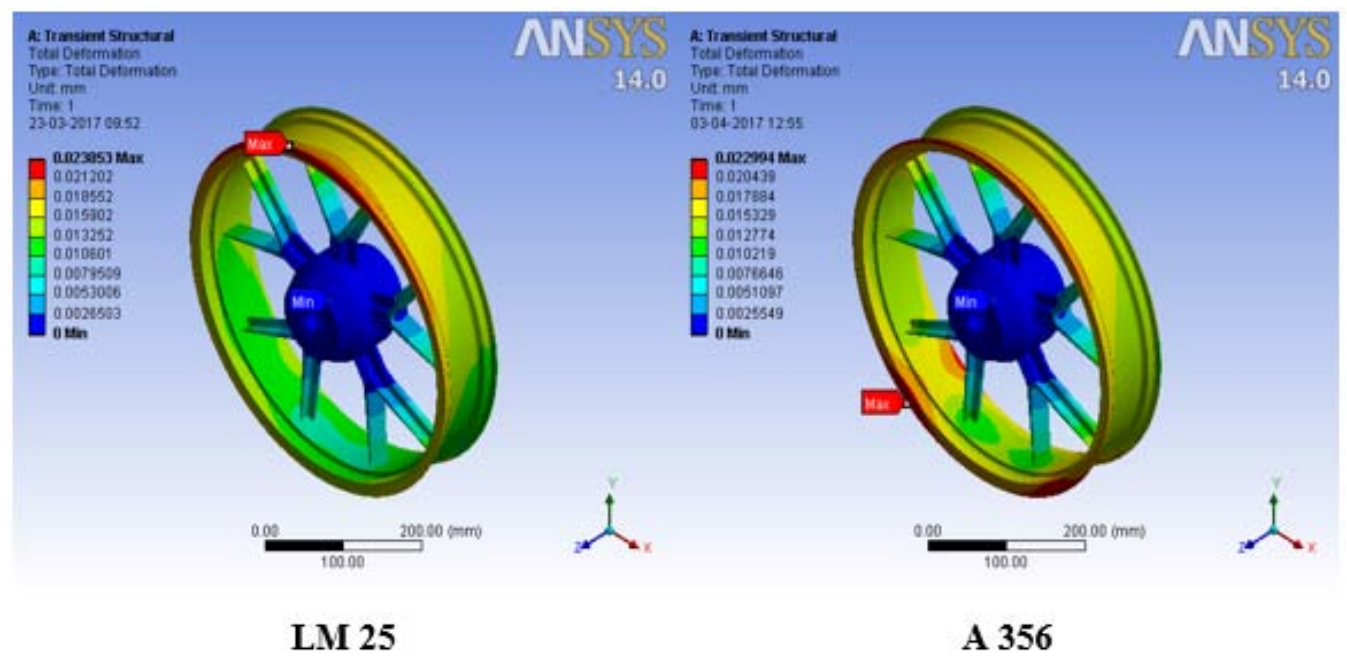

Figure11. Total deformation at speed of $100 \mathrm{kmph}$

The dynamic acceleration at $100 \mathrm{kmph}$ under wet weight conditions, transient structural analysis was performed on the alloy and the maximum deformation for LM 25 (Duke alloy) was found to be $0.023853 \mathrm{~mm}$ whereas, the maximum deformation for A356 was found to be $0.022994 \mathrm{~mm}$ both occurs at the point of loading. 


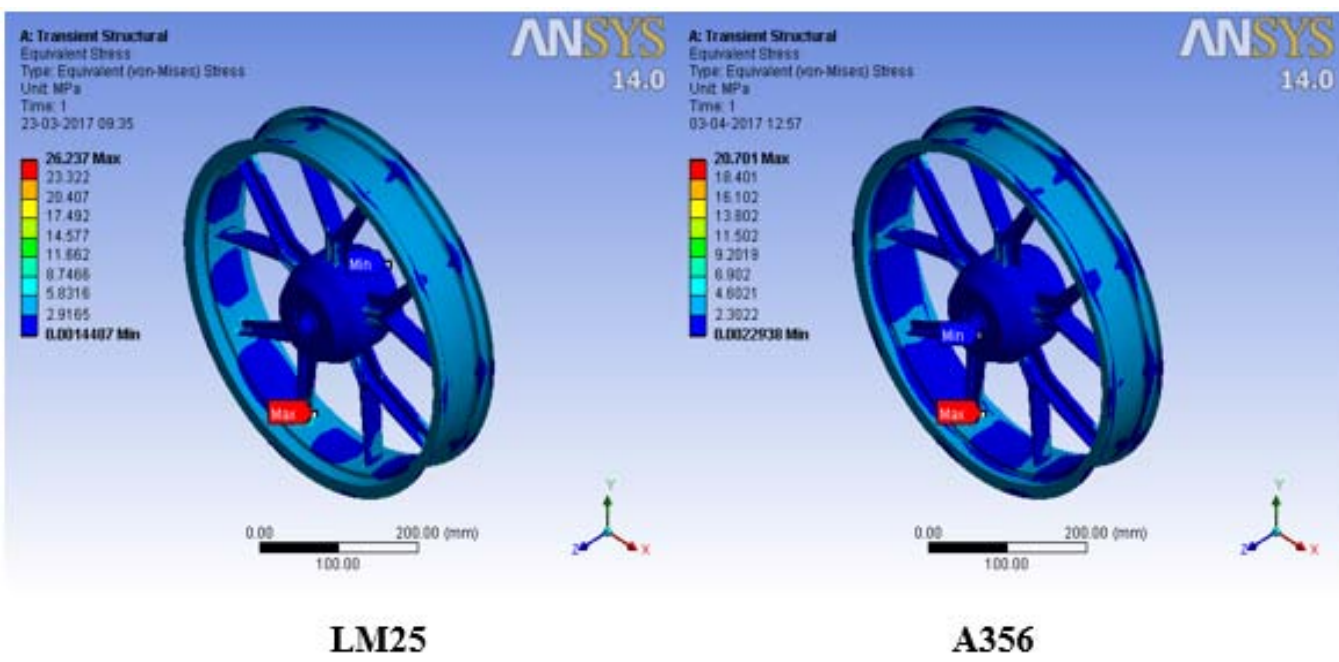

Figure12. Equivalent von-mises stress for the speed of $50 \mathrm{kmph}$

The maximum equivalent (von-mises) stress for LM 25 (Duke Alloy) was found to be 26.237MPa and 20.701 MPa for A356 alloy, which was found to be considerably lower in comparison to the tensile yield and ultimate strength at a speed of $50 \mathrm{kmph}$.

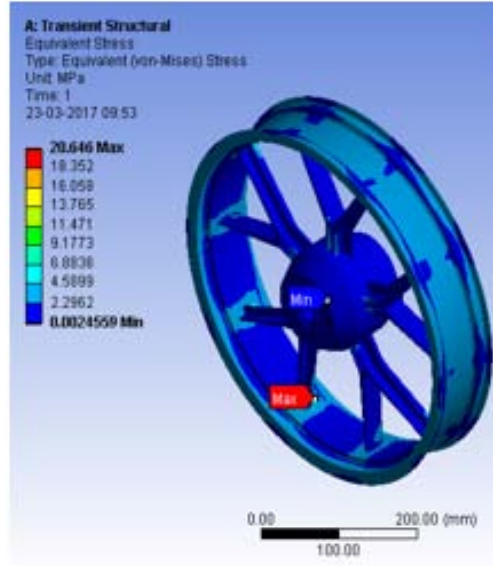

LM25

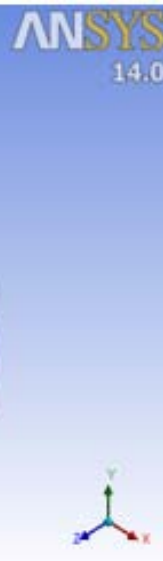

14.0

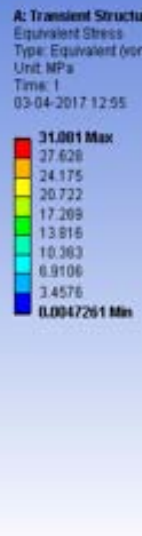

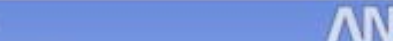

engess

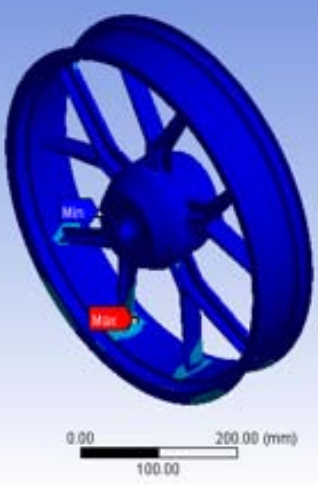

A356

Figure13. Equivalent von-mises stress for the speed of $100 \mathrm{kmph}$

From the above figure, the maximum equivalent (von-mises) stress for LM 25 (Duke Alloy) was found to be 20.646 MPa and 31.081 MPa for A356 alloy, which was found to be considerably lower in comparison to the tensile yield and ultimate tensile strength shown in the table 5 at a speed of $100 \mathrm{kmph}$.

The dynamic braking stress analysis was carried out on the wheel with wet weight for $50 \mathrm{kmph}$ and $100 \mathrm{kmph}$. The figures 14-17 shows the total deformation and equivalent von-misesstresses with LM25 and A356 alloys. 


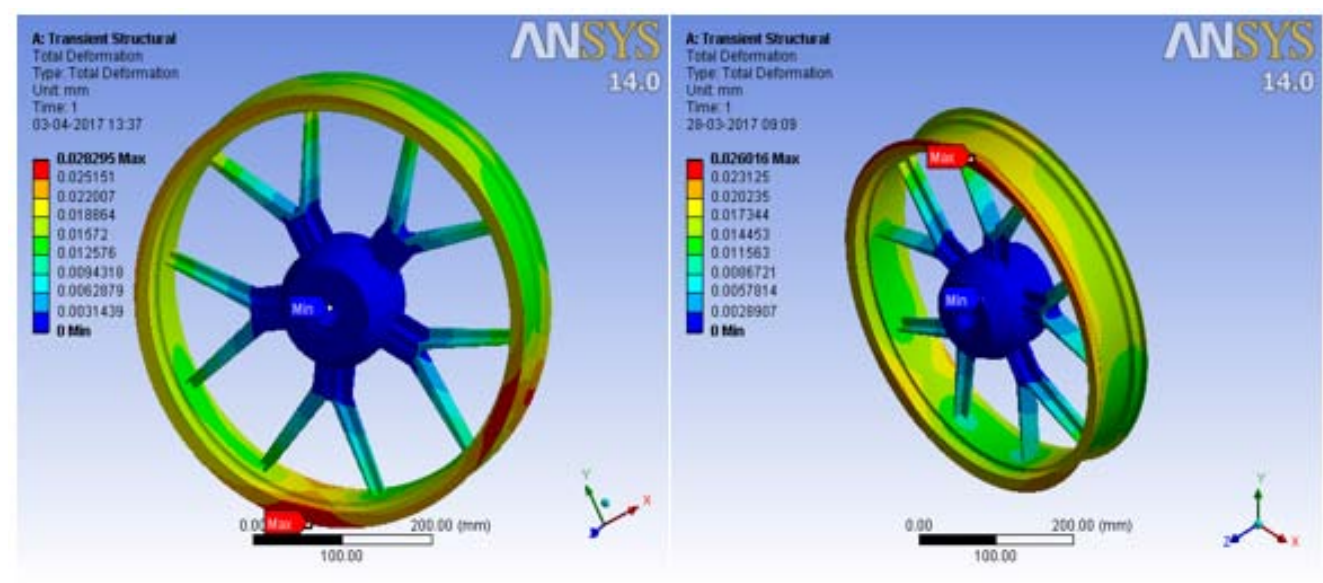

LM 25

A356

Figure14. Total deformation under dynamic braking for the speed of $100 \mathrm{kmph}$

Under dynamic braking at $50 \mathrm{kmph}$ with wet weight condition, transient structural analysis was performed on the alloy and the maximum deformation on LM 25 (Duke alloy) was found to be $0.028295 \mathrm{~mm}$ whereas, the maximum deformation of A356 was found to be $0.026016 \mathrm{~mm}$ both occurring at the point of applied load.

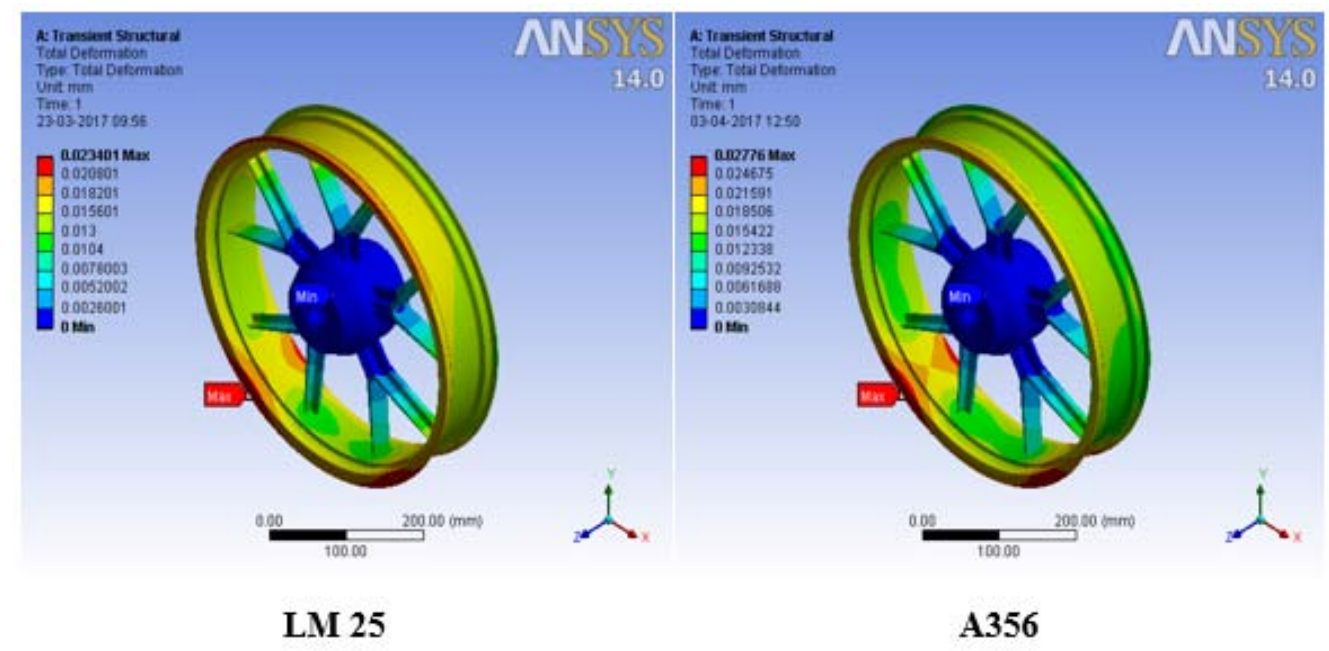

Figure15. Total deformation under dynamic braking for the speed of $100 \mathrm{kmph}$

Similarly, at $100 \mathrm{kmph}$ with wet weight condition, transient structural analysis was performed on the alloy and the maximum deformation on LM 25 (Duke alloy) was found to be $0.023401 \mathrm{~mm}$ whereas, the maximum deformation of A356 was found to be $0.02776 \mathrm{~mm}$ both occurring at the same point where the load was applied. 


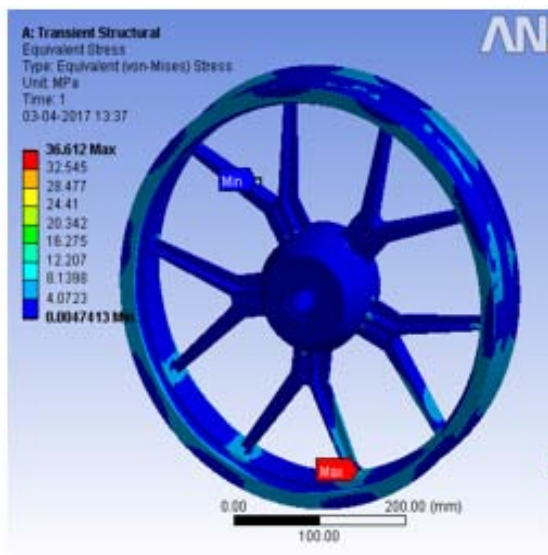

LM 25
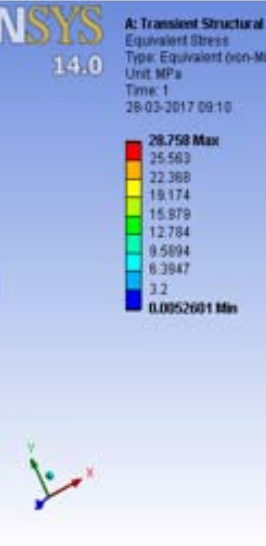

(1)

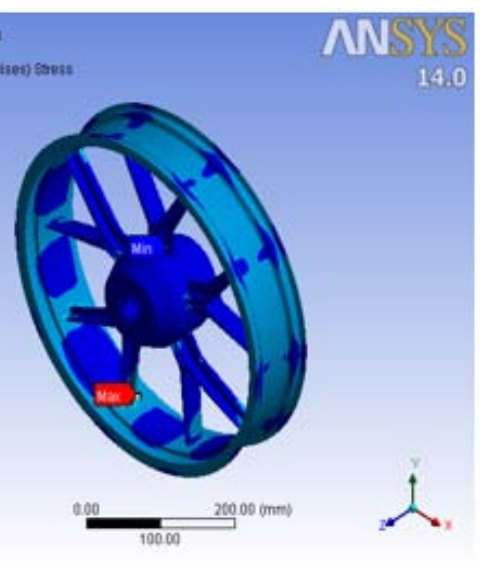

A356

Figure16. Equivalent von-mises stress under dynamic braking for the speed of $50 \mathrm{kmph}$

Figure 16. shows the maximum equivalent (von-mises) stress for LM 25 (Duke Alloy) for the same condition as mentioned and it was found to be 36.612 MPa and 28.758 MPa for A356 alloy, which was found to be considerably lower in comparison to the tensile yield and ultimate strength at a speed of $50 \mathrm{kmph}$.

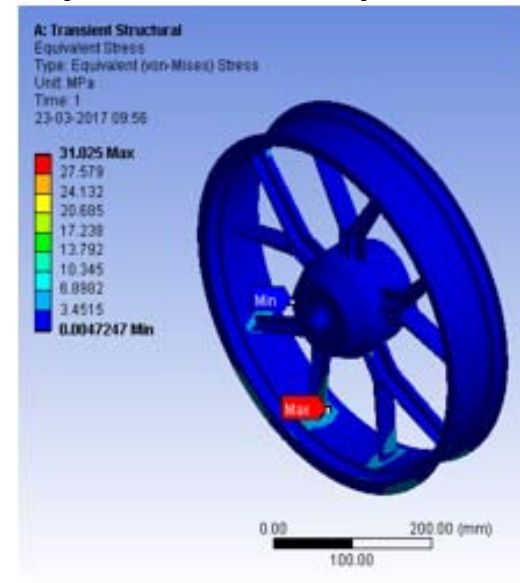

LM 25

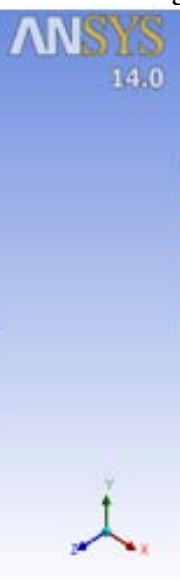

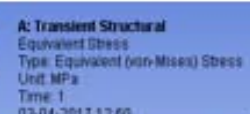

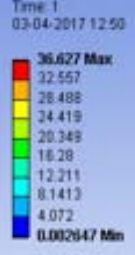

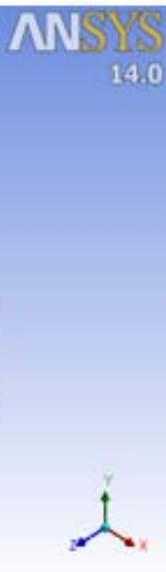

A356

Figure17. Equivalent von-mises stress under dynamic braking for the speed of $100 \mathrm{kmph}$

Similarly, at $100 \mathrm{kmph}$, the maximum equivalent (von-mises) stress for LM 25 (Duke Alloy) was found to be 31.025 MPa and 36.627 MPa for A356 alloy, which was found to be considerably lower in comparison to the tensile yield and ultimate tensile strength at a speed of $100 \mathrm{kmph}$ which is found to be lower than the values shown in table 5 .

The dynamic acceleration test for the front wheel with combined load (wet weight + average weight of two people) was carried out with LM25 and A356 alloy. The figures 18 - 21 shows the total deformation and equivalent vonmises stress for $50 \mathrm{kmph}$ and $100 \mathrm{kmph}$. 


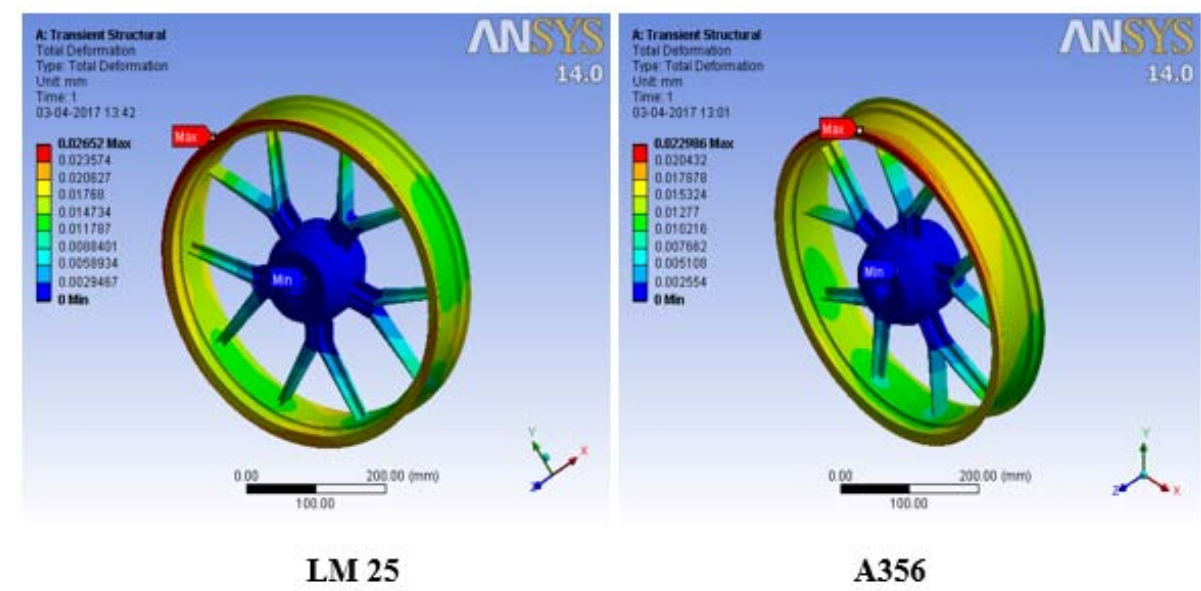

Figure18. Total deformation under dynamic braking with wet weight and average weight of two people for the speed of $50 \mathrm{kmph}$

The above figure shows the total deformation for dynamic acceleration at $50 \mathrm{kmph}$ under wet weight along with a maximum load of two people, and the maximum deformation on LM 25 (Duke alloy) was found to be $0.02652 \mathrm{~mm}$ whereas, the maximum deformation of A356 was found to be $0.022986 \mathrm{~mm}$ at the point of applied load.

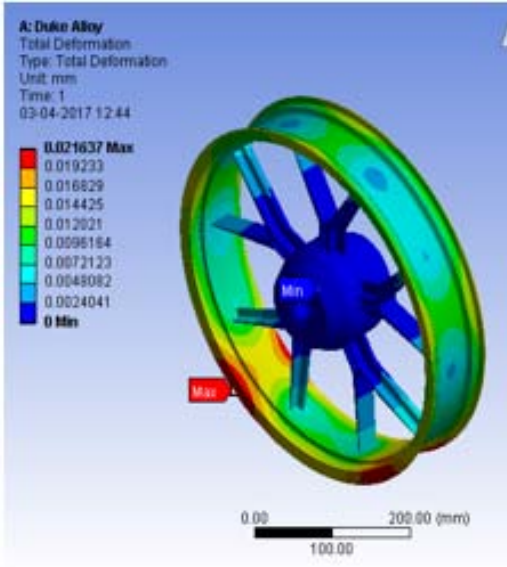

LM 25

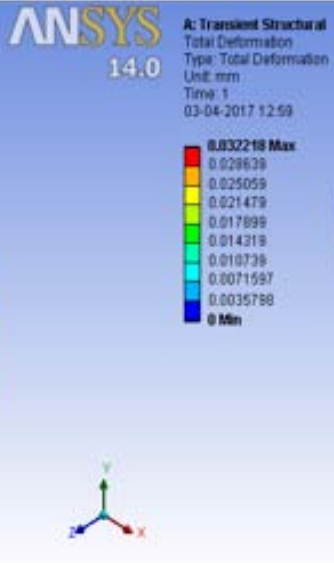

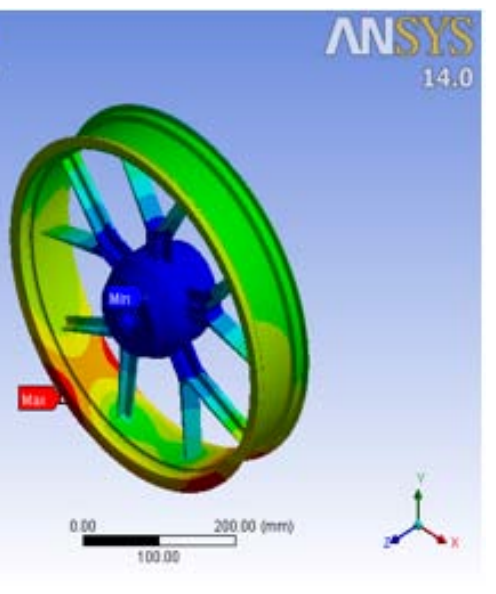

A356

Figure19. Total deformation under dynamic braking with wet weight and average weight of two people for the speed of $100 \mathrm{kmph}$

The dynamic acceleration analysis at $100 \mathrm{kmph}$ under wet weight along with a maximum load of two people was performed on the alloy and the maximum deformation on LM 25 (Duke alloy) was found to be $0.021637 \mathrm{~mm}$ whereas, the maximum deformation of A356 was found to be $0.032218 \mathrm{~mm}$. 


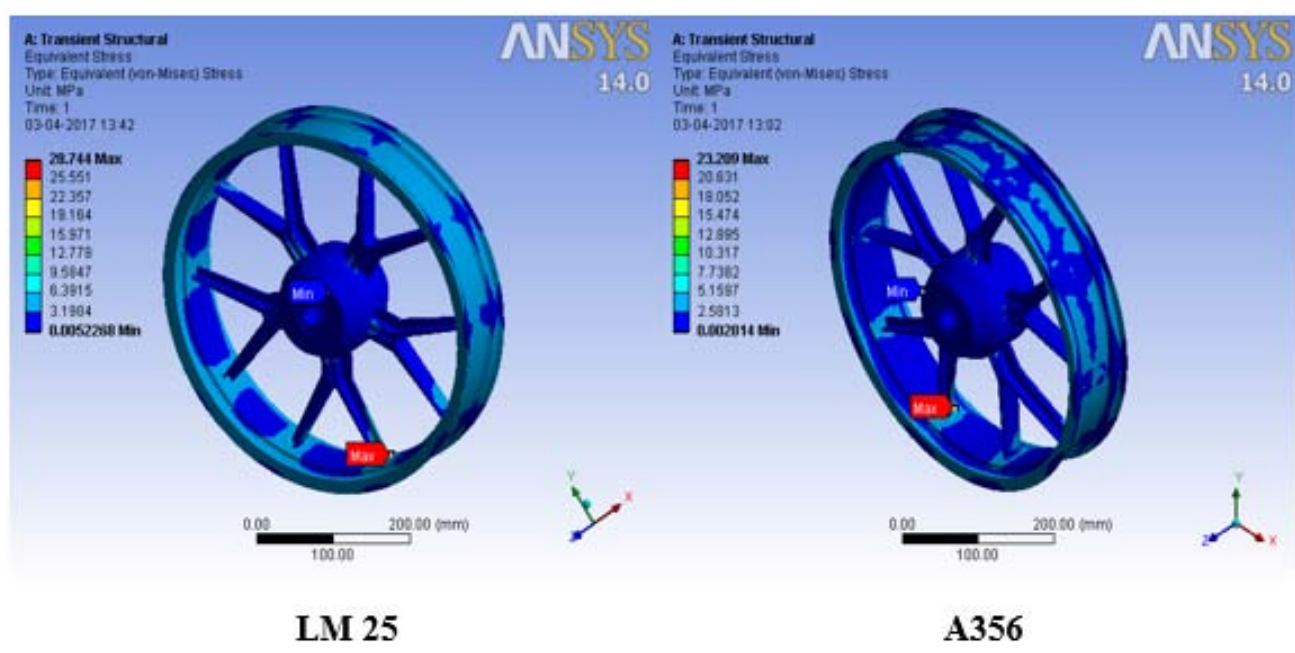

Figure 20. Equivalent von-mises stress under dynamic braking with wet weight and average weight of two people for the speed of $50 \mathrm{kmph}$

Similarly, under the same conditions, the maximum equivalent (von-mises) stress for LM 25 (Duke Alloy) was found to be 28.744 MPa and 23.209 MPa for A356 alloy, which was found to be considerably lower in comparison to the tensile yield and ultimate strength of both the materials.

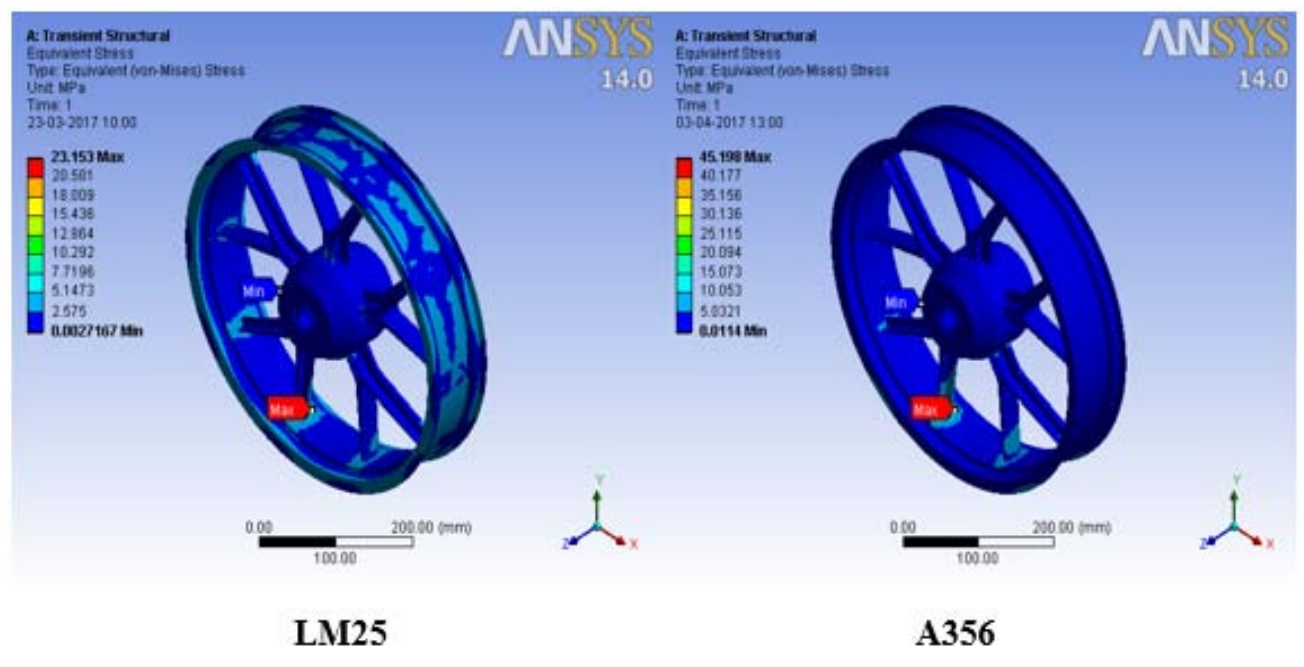

Figure 21. Equivalent von-mises stress under dynamic braking with wet weight and average weight of two people for the speed of $100 \mathrm{kmph}$

The test was done with the above conditions and the maximum equivalent (von-mises) stress for LM 25 (Duke Alloy) was found to be 23.153 MPa and 45.198 MPa for A356 alloy, which was found to be considerably lower in comparison to the tensile yield and ultimatetensile strength of the material.

The dynamic braking test for the front wheel with combined load (wet weight + average weight of two people) was carried out with LM25 and A356 alloy. The figures 22 - 25 show the total deformation and equivalent von-mises stress for $50 \mathrm{kmph}$ and $100 \mathrm{kmph}$. 


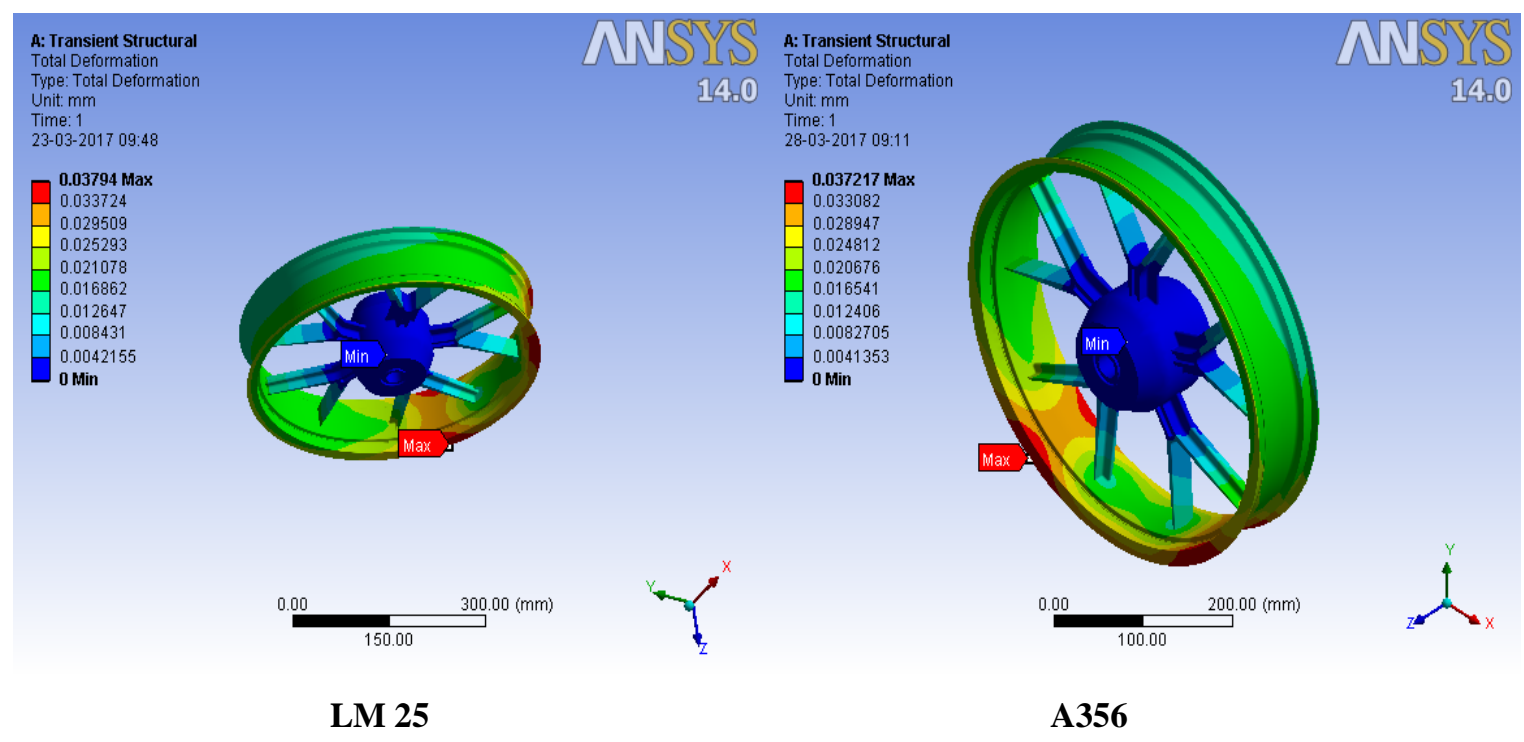

Figure 22. Total deformation under dynamic acceleration with wet weight and average weight of two people for the speed of $50 \mathrm{kmph}$

The above figure shows the total deformation for dynamic braking at $50 \mathrm{kmph}$ under wet weight along with a maximum load of two people, and the maximum deformation on LM 25 (Duke alloy) was found to be $0.03794 \mathrm{~mm}$ and for A356 it was found to be $0.037217 \mathrm{~mm}$ both occurring at the same point of load.

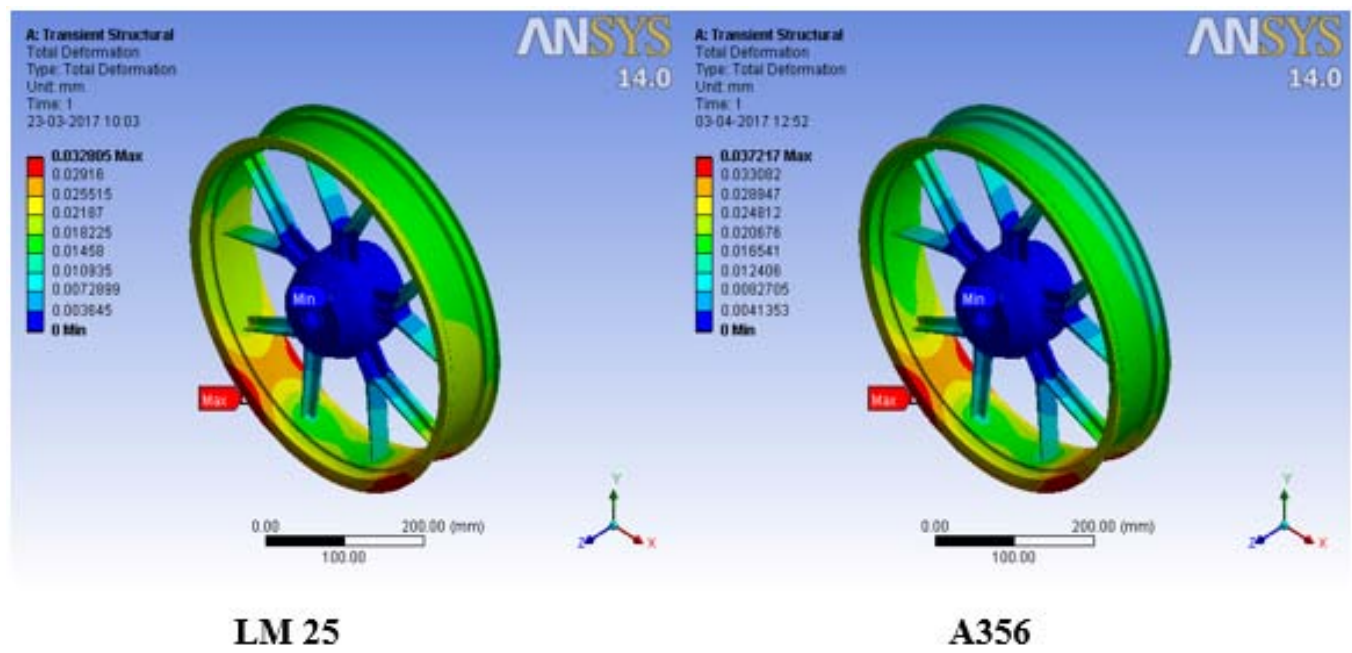

Figure 23. Total deformation under dynamic acceleration with wet weight and average weight of two people for the speed of $100 \mathrm{kmph}$

Similarly at the dynamic acceleration analysis at $100 \mathrm{kmph}$ under wet weight along with a maximum load of two people was performed and the maximum deformation for LM 25 (Duke alloy) was found to be $0.032805 \mathrm{~mm}$ whereas, the maximum deformation for A356 was found to be $0.037217 \mathrm{~mm}$. 


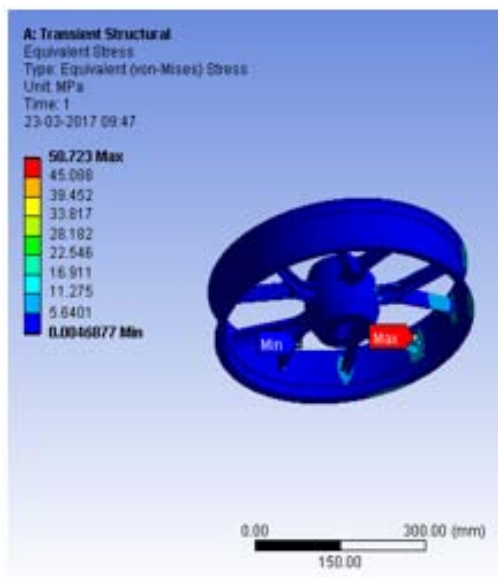

LM 25

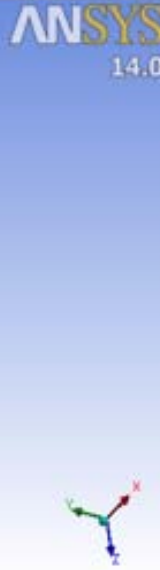

(2)

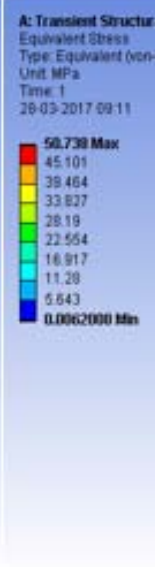

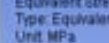

Mien Shen:

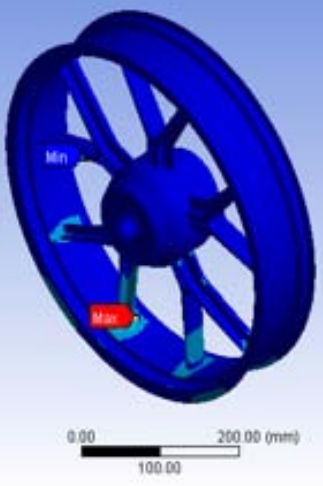

A356

Figure 24. Equivalent von-mises stress under dynamic acceleration with wet weight and average weight of two people for the speed of $50 \mathrm{kmph}$

The above figure shows the equivalent von-mises stress at a speed of $50 \mathrm{kmph}$, the maximum equivalent (VonMises) stress for LM 25 (Duke Alloy) was found to be 50.723MPa and 50.738 MPa for A356 alloy, which was found to be considerably lower in comparison to the tensile yield and ultimate strength of the material.

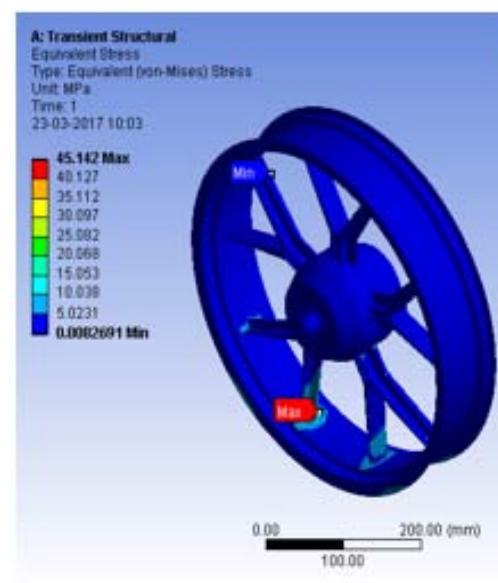

LM 25

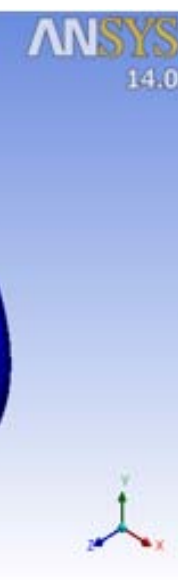

14.0

A: Transimis Shucturil

Equorser Equaters

Urit up:
Tme 1

Tme 1
03042017
0.253

回 $\begin{aligned} & 50.739 \mathrm{Ma} \\ & 45101\end{aligned}$

- 29454

- 32827

2819
-22554

B 16,917

1128
5.643
0.006
$+2$

\section{tev 5 san:}

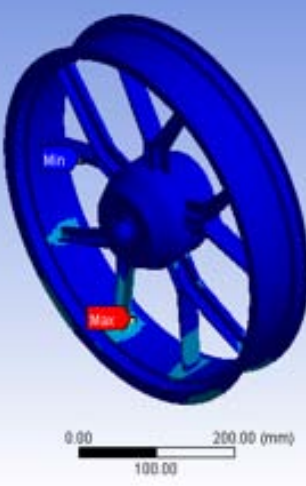

NNSII

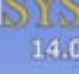

Figure 25. Equivalent von-mises stress under dynamic acceleration with wet weight and average weight of two people for the speed of $100 \mathrm{kmph}$

The same dynamic acceleration test was done for a speed of $100 \mathrm{kmph}$, the maximum equivalent (Von-Mises) stress for LM 25 (Duke Alloy) was found to be $45.142 \mathrm{MPa}$ and $50.738 \mathrm{MPa}$ for A356 alloy, which was found to be considerably lower in comparison to the tensile yield and ultimate strength for the material of the wheel.

\section{A. Comparison of LM25( KTM Duke) and A356 alloy}

The wheel model of the selected two wheeler was analysed with both materials under different load conditions. The results obtained from ANSYS Workbench were compared for the parameters like equivalent von- mises stress and total deformation are shown in the table 6 - 7 given below. 
Table 6. Total deformation at various conditions for both the alloys.

\begin{tabular}{|c|c|c|c|c|c|}
\hline \multirow{3}{*}{ S.no } & \multirow{3}{*}{ Test Condition } & \multicolumn{4}{|c|}{ Total deformation (mm) } \\
\hline & & \multicolumn{2}{|c|}{ LM25 } & \multicolumn{2}{|c|}{ A356 } \\
\hline & & Max. & Min. & Max. & Min. \\
\hline 1 & Static no load & 0.02206 & $\mathbf{0}$ & 0.02163 & $\mathbf{0}$ \\
\hline 2 & Static two People & 0.02597 & $\mathbf{0}$ & 0.02547 & $\mathbf{0}$ \\
\hline 3 & Dynamic acceleration with no load at $50 \mathrm{kmph}$ & 0.02714 & $\mathbf{0}$ & 0.02341 & $\mathbf{0}$ \\
\hline 4 & Dynamic braking with no load at $50 \mathrm{kmph}$ & 0.02829 & $\mathbf{0}$ & 0.02601 & $\mathbf{0}$ \\
\hline 5 & Dynamic acceleration with 2 people at $50 \mathrm{kmph}$ & 0.02652 & $\mathbf{0}$ & 0.02298 & $\mathbf{0}$ \\
\hline 6 & Dynamic braking with 2 people at $50 \mathrm{kmph}$ & 0.03794 & $\mathbf{0}$ & 0.03721 & $\mathbf{0}$ \\
\hline 7 & Dynamic acceleration with no load at $100 \mathrm{kmph}$ & 0.02385 & $\mathbf{0}$ & 0.02299 & $\mathbf{0}$ \\
\hline 8 & Dynamic braking with no load at $100 \mathrm{kmph}$ & 0.02340 & $\mathbf{0}$ & 0.02776 & $\mathbf{0}$ \\
\hline 9 & Dynamic acceleration with 2 people at $100 \mathrm{kmph}$ & 0.02341 & $\mathbf{0}$ & 0.03221 & $\mathbf{0}$ \\
\hline 10 & Dynamic braking with 2 people at $100 \mathrm{kmph}$ & 0.03280 & $\mathbf{0}$ & 0.03721 & $\mathbf{0}$ \\
\hline
\end{tabular}

Table 7. Equivalent von-mises stress at various conditions for the two alloys

\begin{tabular}{|c|c|c|c|c|c|}
\hline \multirow{3}{*}{ S.No } & \multirow{3}{*}{ Test Condition } & \multicolumn{4}{|c|}{ Equivalent von-mises stress (MPa) } \\
\hline & & \multicolumn{2}{|c|}{ Duke Alloy } & \multicolumn{2}{|c|}{ AL 356} \\
\hline & & Max. & Min. & Max. & Min. \\
\hline 1 & Static no load & 26.06 & 0.00866 & 26.06 & 0.00866 \\
\hline 2 & Static two People & 31.518 & 0.00617 & 31.518 & 0.00617 \\
\hline 3 & Dynamic acceleration with no load at $50 \mathrm{kmph}$ & 26.237 & 0.00144 & 20.701 & 0.00228 \\
\hline 4 & Dynamic braking no load at $50 \mathrm{kmph}$ & 36.612 & 0.00474 & 28.758 & 0.00526 \\
\hline 5 & Dynamic acceleration with 2 people at 50 kmph & 28.744 & 0.00522 & 23.209 & 0.00281 \\
\hline 6 & Dynamic braking with 2 people at $50 \mathrm{kmph}$ & 50.723 & 0.00468 & 50.738 & 0.00862 \\
\hline 7 & Dynamic acceleration with no load at $100 \mathrm{kmph}$ & 20.646 & 0.00245 & 31.081 & 0.00472 \\
\hline 8 & Dynamic braking with no load at $100 \mathrm{kmph}$ & 31.025 & 0.00472 & 36.627 & 0.00264 \\
\hline 9 & Dynamic acceleration with 2 people at $100 \mathrm{kmph}$ & 23.153 & 0.00271 & 45.198 & 0.01141 \\
\hline 10 & Dynamic braking with 2 people at $100 \mathrm{kmph}$ & 45.142 & 0.00826 & 50.738 & 0.00620 \\
\hline
\end{tabular}




\section{CONCLUSION}

The static and dynamic analysis under various conditions was performed on the wheel model with LM25 (alloy of KTM DUKE) and A356 alloy and the following conclusions were drawn from the analysis.

1. In the static analysis with wet weight and combined load condition, the total deformation for both the alloy materials showed almost similar deformation.

2. The A356 alloy showed satisfactory results compared to LM25 with lower deformations during dynamic braking and dynamic acceleration at $50 \mathrm{kmph}$, but the same alloy material showed a slight increase in deformation at speed of $100 \mathrm{kmph}$ with wet weight and combined load.

3. The equivalent von-mises stress was found to be identical for both LM25 and A356 under static loading condition with load and no load condition.

4. The A356 alloy showed better results compared to LM25 with lower von-mises stress for dynamic acceleration and dynamic braking with no load and load with two people at speed of $50 \mathrm{kmph}$. However, the von-mises were higher for the same condition at $100 \mathrm{kmph}$.

\section{REFERENCES}

[1] ManjunathBatli, MD.Manazir, N. Chitresh, Malatesh G. Finite Element Analysis on Two Wheeler Alloy Wheel. International Journal of Recent Engineering Science. vol. 27, pp. 1-6, 2016

[2] Mr. Pandurang S. Surushe, Mr. Nitishkumar S. Singh, Mr. Suraj N. Gobade, Mr. Vipin S. Suratkar. Design Analysis and Optimization of Two Wheeler Alloy Wheel, International Journal of Mechanical Engineering and Robotics Research, vol. 5, 2012.

[3] N. Satyanarayana, Sambaiah. Fatigue Analysis of Aluminium Alloy Wheel under Radial Load. International Journal of Mechanical and Industrial Engineering. vol. 2, pp.1 -6, 2012.

[4] Hrishikesh Joshi, Ashish Powar, SanketKhuley and D.P.Yesane. Analysis and Topological Optimization of Motorcycle Front Wheel. International Journal of Current Engineering and Technology. vol. 6, pp. 265-269, 2016

[5] K KalyaniRadha, G Srinivas Kumar and J Paul Rufus Babu. Modeling and Structural Analysis of Alloy Wheel Using COSMOS. European Journal of Advances in Engineering and Technology, vol. 2, pp. 1-6, 2015

[6] Liangmo Wang, Yufa Chen, Chenzhi Wang, Qingzheng Wang. Fatigue Life Analysis of Aluminum Wheels by Simulation of Rotary Fatigue Test. Strojniškivestnik - Journal of Mechanical Engineering, vol. 57, pp. 31-39, 2011.

[7] P. V. Ravi Kumar, R. Satya Meher. Topology Optimization of Aluminium Alloy Wheel. International Journal of Modern Engineering Research, vol. 3, pp. 1548-1553, 2013.

[8] Vijay Sekhar, A.ChandraMouli. Design and Performance Analysis of Alloy Wheels using CATIA ANSYS Modeling Tool. International Journal of Scientific Engineering and Technology Research, vol. 3, pp. 8789-8793, 2014. 